\title{
Coagulase-negative staphylococci and micrococci in urinary tract infections
}

\author{
P. D. MEERS 1 , W. WHYTE ${ }^{2}$, AND G. SANDYS \\ From the Public Health Laboratory, Plymouth, and the Building Services Research Unit, University of Glasgow
}

SYNPOSIS One hundred catalase-positive, coagulase-negative, Gram-positive cocci isolated in significant numbers from the urine of patients with urinary tract infections, provisionally subdivided by their sensitivity to novobiocin, were classified according to a slightly modified version of BairdParker's schemes (1965 and 1972). It appeared that strains of Micrococcus were nearly all of subgroup 3, and that these were important pathogens of young women presenting with urinary infections in general practice. All such strains were resistant to novobiocin. Strains of Staphylococcus were heterogeneous, and were found principally in infections arising in hospital, among older people. Most staphylococci were sensitive to novobiocin.

It is suggested that it is easy and sufficiently accurate to separate staphylococci and micrococci isolated from cases of urinary tract infection on the basis of their sensitivity or resistance to novobiocin. The distinction is useful because of its therapeutic and epidemiological significance.

There is a growing acceptance of the role of some Gram-positive, catalase-positive, coagulase-negative cocci as pathogens of the urinary tract. The division of these organisms into staphylococci or micrococci (as defined by Baird-Parker, 1963) by their differing sensitivity to novobiocin (Mitchell and BairdParker, 1967) has led to the production of evidence in support of the view of Mitchell (1968) that each has a distinct distribution according to the sex and age of the patient concerned. It has also helped in the identification of a specific organism, apparently a micrococcus, as the second most common pathogen of young women with uncomplicated urinary tract infections (Meers, 1974; Maskell, 1974). Because identification in the surveys quoted was presumptive, there was a need to use similar methods in the collection of a number of strains of Grampositive, catalase-positive, coagulase-negative cocci which had been isolated in significant numbers from cases of urinary tract infection, and to compare their classification by Baird-Parker's criteria with separation on novobiocin sensitivity.

\section{Methods}

The collection and examination of urine specimens

${ }^{1}$ Reprint requests to P. D. Meers, Public Health Laboratory, Greenbank Hospital, Plymouth, Devon PL4 8NN

'Address: Building Services Research Unit, 3 Lilybank Gardens, Glasgow G12 8RZ

Received for publication 19 November 1974. was by methods already described (Meers, 1974) Briefly, urine was preserved for transport to the laboratory by the addition of boric acid (Porter and Brodie, 1969), and was cultured by plating with a standard loop onto cysteine-lactose-electrolytedeficient medium (Mackey and Sandys, 1966). Growth equivalent to or greater than $10^{4}$ bacteria per $\mathrm{ml}$ was regarded as significant. One hundred strains of Gram-positive, catalase-positive, coagulasenegative cocci provisionally divided by their sensitivity to novobiocin into either Staphylococcus epidermidis or Micrococcus $\mathrm{sp}$. were collected sequentially in five groups from an equal number of patients. They were classified first into micrococci or staphylococci by using the medium recommended by the International Subcommittee on Taxonomy of Staphylococci and Micrococci (International Subcommittee, 1965) as modified by Chalmers (1972). Further division was then according to Baird-Parker (1963), with carbohydrate reactions carried out on solid media and phosphatase production tested for in tubes as described by Pennock and Huddy (1967). The Voges-Proskauer reaction was carried out in MRVP medium (Oxoid Ltd) using Barritt's method. Anaerobic fermentation of mannitol was determined in the same medium as was used for dividing staphylococci from micrococci, with mannitol instead of glucose. The staphylococci and micrococci were classified into their biotypes or subgroups according to Baird-Parker 
(1965, 1972). Novobiocin sensitivity or resistance was detected using a $5 \mu \mathrm{g}$ disc of the drug on Wellcotest sensitivity test agar (Wellcome Reagents Ltd). Under these conditions all strains were readily separated into those which were sensitive, with zones of inhibition of growth measured radially from the edge of the disc of $8 \mathrm{~mm}$ or more, and those that were resistant, growing right up to, or to within 1 to $2 \mathrm{~mm}$ of the disc.

\section{Results}

A classification by their types of the 100 organisms isolated according to the age, sex, and whether the specimen concerned came from a patient in hospital or in general practice, is given in the table. The 44 micrococci, nearly all of subgroup 3, fitted well into the Baird-Parker scheme, but the 56 staphylococci did not. Of those we designated Staph. epidermidis biotype 1, three did not ferment lactose and 11 did not produce phosphatase. The latter were considered by Baird-Parker (1965) to belong to a separate group, and we have retained this distinction, calling them type $1 / P$. The lactosenegative strains were designated type $1 / \mathrm{L}$. We have distinguished Staph. epidermidis biotype 4 by its ability to utilize mannitol and not by the other biochemical properties, as these would have excluded the majority from the Baird-Parker scheme. These biotype 4 strains were further divided by their ability to produce acid anaerobically from mannitol
(Dean, Williams, Hall, and Corse, 1973); those with this property we have called biotype 4/A.

All the micrococci of subgroup 3, together with the single unclassified micrococcus, were novobiocin resistant. Two of the three subgroup 2 micrococci were novobiocin sensitive, as were all but three of the staphylococci. The staphylococci were generally much more resistant to antimicrobial drugs than were the micrococci. The proportions of strains of staphylococci and micrococci, respectively, found to be resistant to cotrimoxazole (and to sulphonamides) was 34 and $0 \%$, to benzylpenicillin (and ampicillin) 73 and $52 \%$, to tetracycline 61 and $7 \%$, to nitrofurantoin 0 and $0 \%$, to kanamycin 25 and $0 \%$, to nalidixic acid 100 and $100 \%$, and to erythromycin 20 and $2 \%$.

\section{Discussion}

The acceptance of at least some varieties of Grampositive, catalase-positive, coagulase-negative cocci as pathogens of the urinary tract has been slow, despite the appearance of publications documenting their importance over the last 20 years. For instance, Gallagher, Montgomerie, and North (1965) expressed surprise on finding that "coagulase-negative staphylococci', at $14 \%$, were the second most common pathogen in bacteriologically proven cases of urinary tract infection in general practice. Subsequently Dove, Bailey, Gower, Roberts, and de Wardener (1972) reported that $24 \%$ of infections diagnosed by

\begin{tabular}{|c|c|c|c|c|c|c|c|c|c|c|c|c|c|}
\hline \multirow{2}{*}{$\operatorname{Sex}$} & \multirow{2}{*}{ Age } & \multicolumn{8}{|c|}{ Staphylococcus epidermidis Biotype } & \multicolumn{3}{|c|}{ Micrococcus Subgroup } & \multirow{2}{*}{ Totals } \\
\hline & & 1 & & $1 / L$ & $1 / P$ & & 4 & $4 / A$ & & 2 & 3 & $?$ & \\
\hline \multirow{7}{*}{ Males } & $\begin{array}{l}0-4 \\
5-14\end{array}$ & & $l^{1}$ & & & & & & & 1 & 1 & & \\
\hline & $15-24$ & & & & & 2 & & & & & 1 & & 5 \\
\hline & $25-34$ & 1 & & & & & & & & & & & \\
\hline & $35-54$ & & 1 & 1 & & & & & & & & & 30 \\
\hline & $55-74$ & & 10 & $l$ & 1 & 2 & 5 & 1 & 2 & & & & \\
\hline & $75 \div$ & & $I$ & & & 2 & 2 & & & & & & \\
\hline & Subtotals & 1 & 13 & 2 & 1 & 6 & 7 & 1 & 2 & 1 & 1 & & 35 \\
\hline \multirow{8}{*}{ Females } & $\begin{array}{l}0-4 \\
5-14\end{array}$ & & & & & & & & & & & & \\
\hline & $\begin{array}{r}5-14 \\
15-24\end{array}$ & 1 & 1 & & 1 & 1 & & & & & 27 & & 48 \\
\hline & $25-34$ & & 2 & 1 & & & & & & & 8 & 1 & \\
\hline & $35-54$ & 1 & 3 & & & & & 1 & 1 & 2 & 3 & & 17 \\
\hline & $55-74$ & 1 & 3 & & & 2 & & & 1 & & & & \\
\hline & $75-$ & 1 & & & & & 2 & & & & & & \\
\hline & Subtotals & 4 & 9 & 1 & 1 & 3 & 2 & 1 & 2 & 2 & 39 & 1 & 65 \\
\hline & Totals & & $7^{22}$ & $3^{3}$ & 2 & $1^{9}$ & $9^{9}$ & ${ }^{2} 6$ & 4 & $3_{3}$ & $\begin{array}{l}40 \\
40\end{array}$ & $1_{1}$ & 100 \\
\hline
\end{tabular}

Table The distribution of types of Gram-positive, catalase-positive, coagulase-negative cocci isolated in significant numbers from the urine of patients submitted for examination because they were thought to have urinary tract infections

${ }^{1}$ Hospital patients in italic, those from general practice in ordinary type.

Types according to Baird-Parker (1965 and 1972) with the following additions: 1/L lactose-negative type 1 strains; 1/P Phosphatase-negative type 1 strains; 4/A type 4 strains which produce acid anaerobically from mannitol; ? Strains not conforming to any type 
suprapubic aspiration of urine from women in general practice were due to "coagulase-negative staphylococci' (not further identified). It was recognized quite early (Pereira, 1962; Mitchell, 1964) that there was at least one discrete group of closely related organisms among the apparent pathogens covered by the wide definition above, but proof of this had to await the development of an acceptable classification. This was provided by Baird-Parker (1963), who used a number of biochemical criteria to separate Gram-positive, catalase-positive cocci into staphylococci and micrococci, and to subdivide them further into subgroups or biotypes. The application of this classification to urinary bacteriology (Alder, Brown, and Mitchell, 1966; Roberts, 1967) led Mitchell (1968) to observe that infections with these organisms which result from instrumentation of, or abnormalities in, the urinary tract, were usually due to one of the staphylococcal types, while cystitis in otherwise healthy women was often caused by strains of the subgroup 3 micrococcus, a finding supported by Kerr (1973). It was noted (Mitchell and Baird-Parker, 1967) that a provisional separation of staphylococci and micrococci could be made on the basis of novobiocin sensitivity, the former being sensitive and the latter resistant. This simple property has been used by some workers to distinguish between these organisms when isolated in significant numbers from the urine of those thought to have an infection, with results that have supported Mitchell's view. A survey (Meers, 1974) of 3271 presumptive urinary pathogens included 155 coagulase-negative staphylococci and 116 micrococci, separated by their sensitivity to novobiocin. The staphylococci were found chiefly in the urine of patients of both sexes at either end of the age span, who were in hospital, while the micrococci were confined almost exclusively to women between the ages of 15 and 34 presenting with urinary infections in general practice. Another survey (Maskell, 1974) of 2541 cases of urinary infection gave similar results. Both these surveys produced evidence which suggested that the micrococcus was more productive of inflammatory exudate than any other urinary pathogen, and showed that for patients in general practice in the sex and age group quoted above, the Micrococcus subgroup 3, as provisionally identified, was the second most common pathogen. The current survey shows that most infections of the urinary tract by Gram-positive, catalase-positive, coagulase-negative cocci in general practice are due to the Micrococcus subgroup 3. It also confirms the general validity of the provisional identification of the Micrococcus subgroup 3 on the basis of novobiocin resistance. In our series, $7 \%$ of organisms would have been misdiagnosed on this basis, as three staphylococci would have been labelled micrococci, and two Micrococcus subgroup 2 would have been called staphylococci. In addition two micrococci other than of subgroup 3 would have been incorrectly identified as being of that type. However, we think this degree of error in a simple practical procedure is acceptable, because its main function is to alert those concerned to the way these organisms, when acting as pathogens, are distributed in the community. The object of this education is to influence the choice of antimicrobial to be used in therapy, either before a sensitivity result is available, or where a bacteriological examination is not intended. The sensitivity to various antimicrobial agents of the staphylococci and micrococci surveyed, given in the Results section, shows the need for this. The proportions of resistant strains found agree closely with the results of tests on a larger number of similar organisms recently gathered in the same area (Meers, 1974), and indicate that nalidixic acid is a poor choice for the 'blind' treatment of urinary infection in general practice, and that ampicillin (or amoxycillin), though an improvement, is not as good as cotrimoxazole, and that sulphonamides on their own are not to be ignored. In hospital, where staphylococci predominate over micrococci, the advice concerning nalidixic acid stands, but ampicillin is of reduced value, and a significant number of cases of resistance to cotrimoxazole are found.

Møller, Christiansen, and Mortensen (1973) have suggested that urinary strains of micrococci should be reclassified as staphylococci because their DNA base composition is more like the latter, and Mitchell (1968) reported that strains of Micrococcus subgroup 3 have certain cell-wall constituents in common with Staph. aureus. There is also a move to reclassify micrococci of subgroups $1-4$ as biotypes of Staph. saprophyticus (Baird-Parker, 1974). No matter what the taxonomic outcome, it is clear, however, that there exists a discrete, homogeneous group of Gram-positive, catalase-positive, coagulasenegative, novobiocin-resistant cocci with a special predilection for the urinary tract of apparently normal young women, in whom they accompany a severe, acute inflammatory process second in frequency only to Escherichia coli.

The work done by W.W. is supported by the Medical Research Council, U.K.

References

Alder, V. G., Brown, A. M., and Mitchell, R. G. (1966). The tellurite reactions of coagulase negative staphylococci and micrococci. J. appl. Bact., 29, 304-307.

Baird-Parker, A. C. (1963). A classificatiun of micrococci and staphylococci based on physiological and biochemical tests. J. gen. Microbiol., 30, 409-427. 
Baird-Parker, A. C. (1965). The classification of staphylococci and micrococci from world-wide sources J. gen. Microbiol., 38, 363-387.

Baird-Parker, A. C. (1972). Classification and identification of staphylococci and their resistance to physical agents. In The Staphylococci, edited by J. O. Cohen, pp. 1-20. Wiley, New York.

Baird-Parker, A. C. (1974). Personal communication.

Chalmers, A. (1972). A modification of the oxidation/fermentation test for the classification of Micrococcaceae. Med. Lab. Technol., 29, 379-384.

Dean, B. A., Williams, R. E. O., Hall, F. and Corse, J. (1973). Phage typing of coagulase-negative staphylococci and micrococci. J. Hyg. (Lond.), 71, 261-270.

Dove, G. A., Bailey, A. J., Gower, P. E., Roberts, A. P., and de Wardener, H. E. (1972). Diagnosis of urinary-tract infection in general practice. Lancet, 2, 1281-1283.

Gallagher, D. J. A., Montgomerie, J. Z., and North, J. D. K. (1965). Acute infections of the urinary tract and the urethral syndrome in general practice. Brit. med. J., 1, 622-626.

International Subcommittee on Taxonomy of Staphylococci and Micrococci (1965). Recommendations. Int. Bull. bact. Nomencl. Taxon., 15, 109-110.

Kerr, H. (1973). Urinary infection caused by Micrococcus subgroup 3. J. clin. Path., 26, 918-920.

Mackey, J. P., and Sandys, G. H. (1966). Diagnosis of urinary infections. (Letter) Brit. med. J., 1, 1173.
Maskell, R. (1974). Importance of coagulase-negative staphylococci as pathogens in the urinary tract. Lancet, 1, 1155-1158.

Meers, P. D. (1974). The bacteriological examination of urine: a computer-aided study. J. Hyg. (Lond.), 72, 229-244.

Mitchell, R. G. (1964). Urinary tract infections due to coagulasenegative staphylococci. J. clin. Path., 17, 105-106.

Mitchell, R. G. (1968). Classification of Staphylococcus albus strains isolated from the urinary tract. J. clin. Path., 21, 93-96.

Mitchell, R. G., and Baird-Parker, A. C. (1967). Novobiocin resistance and the classification of staphylococci and micrococci. J. appl. Bact., 30, 251-254.

Møller, J. K., Christiansen, C., and Mortensen, N. (1973). DNA base composition of coagulase-negative staphylococci associated with urinary tract infection. Acta path. microbiol. scand., Sect. B, 81, 559-562.

Pennock, C. A., and Huddy, R. B. (1967). Phosphatase reaction of coagulase-negative staphylococci and micrococci. J. Path. Bact., 93, 685-688.

Pereira, A. Torres (1962). Coagulase-negative strains of staphylococcus possessing antigen 51 as agents of urinary infection. J. clin. Path., 15, 252-253.

Porter, I. A., and Brodie, J. (1969). Boric acid preservation of urine samples. Brit. med. J., 2, 353-355.

Roberts, A. P. (1967). Micrococcaceae from the urinary tract in pregnancy. J. clin. Path., 20, 631-632. 